\title{
Effects of some factors on insensible weight loss in grazing sheep
}

\author{
B Dumont 1, PD Penning 2, RJ Orr 2, P D'Hour ${ }^{1}$ \\ 1 INRA, Laboratoire Adaptation des Herbivores aux Milieux, \\ Theix, 63122 Saint-Genès-Champanelle, France; \\ 2 AFRC Institute of Grassland and Environmental Research, \\ North Wyke Research Station, Okehampton, Devon EX20 2SB, UK
}

\begin{abstract}
Weight changes during grazing, with an allowance for insensible weight loss (IWL), are sometimes used to estimate intake (Penning and Hooper, 1985). This technique requires an accurate estimate of the IWL as it can account for up to $25 \%$ of the apparent intake rate by grazing sheep. Two experiments were conducted to investigate the effects of variation between individual animals, fasting, herbage species and ambient temperature on the measurement of IWL.
\end{abstract}

In experiment 1, 18 dry, mature Scottish Halfbred ewes grazed 2 pastures, perennial rye-grass $(\mathrm{Rg})$ or white clover (Wc) after a fast of $24 \mathrm{~h}(\mathrm{~F})$ or when unfasted (control, C). For each treatment IWL was measured on $3 \mathrm{~d}$, before the evening meal. IWL was estimated by fitting animals with bags to collect faeces and urine and muzzles to prevent grazing. Animals were then weighed using an electronic balance $(0-240 \mathrm{~kg} \pm 10 \mathrm{~g})$ interfaced to a microcomputer, turned out to pasture for $1 \mathrm{~h}$ and weighed again (Penning and Hooper, 1985). IWL was calculated as the difference between the 2 weighings. The effects of fasting, pasture, temperature $\left(16.4-20.2^{\circ} \mathrm{C}\right)$ and liveweight (27.8-35.4 $\mathrm{kg}^{0.75}$ ) were considered in analyses of variance. In experiment 2, 16 of the 18 sheep were used in 4 groups of 4 animals. IWL was measured, on 4 occasions each day using 1 group of animals for each measurement. Animals were measured for $1 \mathrm{~d}$ on $\mathrm{Rg}$ and, after acclimatisation, for $1 \mathrm{~d}$ on Wc. The effects of pasture, individuals and temperature $\left(15.2-21.7^{\circ} \mathrm{C}\right)$ were considered here.

In experiment 1 there was no significant interaction between pasture and fasting. IWL was respectively 0.4 and $1.4 \mathrm{~g} \cdot \mathrm{min}^{-1}$ higher on Wc than $\mathrm{Rg}(P<0.01)$ and for $\mathrm{C}$ than $\mathrm{F}(P<0.001)$. IWL varied between individuals $(P<0.001)$ from 2.6 to $5.0 \mathrm{~g} \cdot \mathrm{min}^{-1}$ and increased by $0.23( \pm 0.07)$ g. $\min ^{-1} .{ }^{\circ} \mathrm{C}^{-1}(P<0.002)$. This model accounted for $54 \%$ of the total variance for IWL with a CV of $26 \%$. An increase in IWL of $0.08( \pm 0.04)$ g. min $^{-1} . \mathrm{kgLW} \mathbf{W}^{0.75-1}(P<0.05)$ was also observed. In experiment 2, no differences were found between $W_{C}$ and $\mathrm{Rg}$ but differences between individuals $(P<0.025)$ and temperature $(+0.19 \pm$ 0.07 g.min ${ }^{-1} .{ }^{\circ} \mathrm{C}^{-1} ; P<0.02$ ) still had an effect. This model accounted for $84 \%$ of the total variance for IWL with a CV of $14 \%$. In conclusion there are consistent differences between individual animals, which is important when estimating intake and requires that intake rate is corrected for IWL measured on the same animal. A weak but significant effect of liveweight explains part of these differences. As IWL consists mainly of water loss due to respiratory evaporative cooling, temperature also has an effect on IWL, justifying its use as a correction factor when temperature variation over measurement periods is wide. This approach has been used by Murray (1991) in Africa. Finally, higher IWL for treatment $\mathrm{C}$ compared with $\mathrm{F}$ may be explained by differences in general metabolic activity (heat and water production, gaseous losses etc) with different gut fill or forage consumption.

Murray MG (1991) J Anim Ecol 60, 1029-1045

Penning PD, Hooper GE (1985) Grass For Sci $40,79-84$ 